\title{
DIET-RELATED MODIFICATION OF CUTICULAR HYDROCARBON PROFILES OF THE ARGENTINE ANT, Linepithema humile, DIMINISHES INTERCOLONY AGGRESSION
}

\author{
GRZEGORZ BUCZKOWSKI, ${ }^{1,3}$ RANJIT KUMAR, ${ }^{2}$ \\ STEVEN L. SUIB ${ }^{2}$ and JULES SILVERMAN ${ }^{1, *}$ \\ ${ }^{1}$ Department of Entomology, North Carolina State University, Raleigh, \\ North Carolina 27695-7613, USA \\ ${ }^{2}$ Department of Chemistry, University of Connecticut, Storrs, Connecticut 06269-3060, USA
}

(Received August 3, 2004; accepted November 29, 2004)

\begin{abstract}
Territorial boundaries between conspecific social insect colonies are maintained through a highly developed nestmate recognition system modulated by heritable and, in some instances, nonheritable cues. Argentine ants, Linepithema humile, use both genetic and environmentally derived cues to discriminate nestmates from nonnestmates. We explored the possibility that intraspecific aggression in the Argentine ant might diminish when colonies shared a common diet. After segregating recently field-collected colony pairs into high or moderate aggression categories, we examined the effect of one of three diets: two hydrocarbon-rich insect prey, Blattella germanica and Supella longipalpa, and an artificial (insect-free) diet, on the magnitude of aggression loss. Aggression diminished between colony pairs that were initially moderately aggressive. However, initially highly aggressive colony pairs maintained high levels of injurious aggression throughout the study, independent of diet type. Each diet altered the cuticular hydrocarbon profile by contributing unique, diet-specific cues. We suggest that acquisition of common exogenous nestmate recognition cues from shared food sources may diminish aggression and promote fusion in neighboring colonies of the Argentine ant.
\end{abstract}

Key Words-Argentine ant, cuticular hydrocarbons, diet, invasive ants, nestmate recognition, unicoloniality.

* To whom correspondence should be addressed. E-mail: jules_silverman@ncsu.edu

${ }^{3}$ Current address: Department of Entomology, Purdue University, West Lafayette, Indiana 47907, USA. 


\section{INTRODUCTION}

Social insects have evolved a highly developed recognition system that forms the basis of social structure and communication. The signals used in nestmate recognition are primarily under genetic control; however, exogenous cues derived from nest materials (Gamboa et al., 1986; Stuart, 1987) or diet (Jutsum et al., 1979; Obin and Vander Meer, 1988; Le Moli et al., 1992; Liang and Silverman, 2000) may also play a role. Cuticular hydrocarbons have long been considered important mediators of nestmate recognition in ants (Vander Meer and Morel, 1998), with recent evidence supporting a direct role (Lahav et al., 1999; Liang and Silverman, 2000). However, the relative contribution of heritable and environmentally derived cues, including hydrocarbons, to the recognition profile is not known. Irrespective of the source, workers must learn colony-specific cues and must be able to properly evaluate cues present on newly encountered workers. Recognition cues are generally dynamic and may change throughout the life of the colony (Vander Meer et al., 1989) and exhibit seasonal variation (Ichinose, 1991). Therefore a worker must continually update its perception of colony odor in response to endogenous and external changes.

The Argentine ant, Linepithema humile, is one of several invasive ants in which the relative loss of territorial behavior is thought to contribute to invasion success. Introduced $L$. humile populations are unicolonial and frequently very large, and they often dominate native ant species (Suarez et al., 1999). Nestmate recognition in the Argentine ant is influenced by genetic (Tsutsui et al., 2000, 2003; Suarez et al., 2002) and environmental (Chen and Nonacs, 2000; Liang and Silverman, 2000) inputs. Holway et al. (1998) and Suarez et al. (2002) reported that aggression persisted between $L$. humile colonies despite maintenance under uniform rearing conditions, whereas Chen and Nonacs (2000) observed a decrease in L. humile intercolony aggression following 2 mo of laboratory rearing. Whereas Tsutsui et al. (2000) demonstrated a significant inverse relationship between L. humile genetic similarity and intercolony aggression, the colony pairs used by Holway et al. (1998), Chen and Nonacs (2000), and Suarez et al. (2002) were not subjected to genetic analysis. Therefore the observed changes (or lack thereof) in aggression may have resulted from different degrees of genetic similarity, with aggression between the most dissimilar pairs unlikely to change despite similar rearing conditions.

Whereas it has been suggested that loss of genetic diversity is primarily responsible for the unicolonial population structure observed in introduced Argentine ant populations (Tsutsui et al., 2000), the role of shared environmental cues such as diet in promoting unicoloniality is unknown. Shared dietary components, specifically hydrocarbons, for colonies displaying low intercolony genetic differentiation, may mask subtle inherent between-colony distinctions, thereby promoting fusion of adjacent colonies. Liang and Silverman (2000) and 
Silverman and Liang (2001) demonstrated the potential of prey hydrocarbons to alter nestmate recognition in the Argentine ant, with worker exposure to specific prey eliciting aggression from colony mates. Of the many different prey exposed to L. humile workers, contact with the brown-banded cockroach, Supella longipalpa, induced the highest level of intracolony aggression (Liang et al., 2001). S. longipalpa has several hydrocarbons that are identical or similar to those of L. humile, which may be important in L. humile nestmate recognition (Liang et al., 2001). We propose that the opposite process can occur, whereby key S. longipalpa-acquired recognition chemicals attenuate differences between L. humile colonies, thus diminishing intercolony aggression. We compare intercolony aggression levels before and after continuous exposure to diets including S. longipalpa, Blattella germanica, or artificial diet and also measure changes in key prey-specific hydrocarbons on L. humile cuticle. We hypothesize that diets with $S$. longipalpa will diminish aggression the most. By documenting changes in intercolony aggression following exposure to sources of exogenous recognition cues, we hope to develop a deeper understanding of the dynamic nature of Argentine ant nestmate discrimination and its potential role in structuring populations in this invasive insect.

\section{METHODS AND MATERIALS}

Collection and Rearing of Laboratory Colonies. We used 11 colonies of Argentine ants (L. humile) from 11 sites in the southeastern USA-North Carolina (six): Chapel Hill (chh), Emerald Isle (emi), Greenville (gnc), Jacksonville (jac), Shallotte (sch), and Winston-Salem (for); South Carolina (two): Greenville (hto) and Greer (gwm); and Georgia (three): Barnesville (bch), Fayetteville (fay), and Griffin (grf). Ants were collected from a variety of habitats, including landscaped residential lots, natural wooded areas, or sand dunes. For each location, we established three large colonies consisting of 5000-10,000 workers, a few hundred queens, and numerous brood. Colonies were maintained in soil-free, Fluon-coated trays. Nests were plastic dishes filled with moist grooved plaster. Colonies were reared on one of three diets, each of which included a $25 \%$ sucrose solution ad libitum and hard-boiled eggs once a week: artificial noninsect diet (Bhatkar and Whitcomb, 1970), S. longipalpa male and female adults, or B. germanica male and female adults. All colonies were maintained at $24 \pm 1{ }^{\circ} \mathrm{C}, 50 \pm 10 \% \mathrm{RH}$, and a $12: 12 \mathrm{hr}$ light/dark cycle.

Aggression Tests (Nestmate Recognition Bioassay). We assessed the initial level of aggression between 18 colony pairs (listed below) with an assay that measured the level of aggression in single worker introductions into a foreign colony. This behavioral assay has low variance among replicates within the same colony pairing (Roulston et al., 2003). Individual intruder workers were 
collected on a toothpick and introduced into rearing trays $(52 \times 38 \mathrm{~cm})$ containing a resident colony $(\sim 10,000$ workers $)$. The responses of resident workers toward the intruder were recorded, and aggression was scored using the 0-4 scale of Suarez et al. (1999). The intruder was discarded after each trial, and subsequent trials were conducted when the residents were no longer visibly agitated (5-10 $\mathrm{min})$. Ten replicates per colony pair were performed: five replicates with colony 1 as the resident and five replicates with colony 1 as the intruder. The observer who recorded the aggression level did not know the identity of the interacting colonies and was unfamiliar with the hypothesis being tested. All assays to estimate the initial aggression levels were performed within a week of collection and extraction of ants from the original nesting substrate. Data were analyzed as the maximum score per trial (Roulston et al., 2003).

Our preliminary observations indicated a possible relationship between the initial level of aggression displayed by a colony pair and that colony pair losing aggression over time, with pairs having high initial aggression maintaining it over time and colonies with moderate levels of initial aggression becoming nonaggressive. We define moderate aggression as an average score of 3.0 or lower and high aggression as a score of 3.0 or higher on a $0-4$ scoring scale (Suarez et al., 1999). This assignment is based on aggression above level 3 being injurious (biting, stinging), whereas aggression below level 3 is noninjurious (mutual antennation, avoidance). Eight colony pairs were moderately aggressive: gnc-fay, for-emi, chh-bch, for-gnc, chh-grf, chh-hto, gwm-sch, and gwm-fay, and 10 colony pairs were highly aggressive: jac-fay, jac-sch, jac-chh, emi-bch, jac-hto, emi-grf, emi-chh, emi-hto, emi-sch, and jac-bch. Aggression assays and hydrocarbon analyses were repeated $140 \mathrm{~d}$ later for all three dietary regimes to assess changes in nestmate recognition patterns and to determine whether behavioral changes were consistent with hydrocarbon patterns. Aggression assays were performed again at day 224 to determine whether aggression had further declined with prolonged laboratory rearing.

Extraction, Isolation, and Chemical Analysis of Cuticular Hydrocarbons. Ants were killed by freezing $\left(-20^{\circ} \mathrm{C}\right)$ prior to hydrocarbon extraction. External lipids were extracted from the cuticle by immersing 10 whole thawed ants in 1-ml hexane for $10 \mathrm{~min}$, followed by a brief second rinse. The samples were gently shaken for the first and last $20 \mathrm{sec}$ of the soak period. Hexane extracts were concentrated under nitrogen to $\sim 100 \mu$ l and applied to prewetted (hexane) Pasteur pipette minicolumns filled with $500 \mathrm{mg}$ of silica gel (63-200 mesh size, Selecto Scientific, GA, USA). The hydrocarbon fraction was eluted with 6-ml hexane and blown to dryness under nitrogen. The extract was redissolved in 5$\mu \mathrm{l}$ hexane, and $1 \mu \mathrm{l}$ was analyzed (two ant equivalents). Gas chromatography (GC) was carried out using an HP 5890 gas chromatograph equipped with a DB-1 column $(30 \mathrm{~m} \times 0.25 \mathrm{~mm} \times 0.25 \mu \mathrm{m}$ film thickness $)$ and interfaced with a G1045A Chemstation (version A05.01). Oven temperature was held at $40^{\circ} \mathrm{C}$ 
for $2 \mathrm{~min}$, then increased to $200^{\circ} \mathrm{C}$ at $20^{\circ} \mathrm{C} / \mathrm{min}$, and then to $310^{\circ} \mathrm{C}$ at $40^{\circ} \mathrm{C} / \mathrm{min}$. The injector and flame-ionization detector were at 270 and $320^{\circ} \mathrm{C}$, respectively. Helium was the carrier gas, and the make-up gas was nitrogen. Quantitative data were obtained by integrating the peaks and calculating the percent area under each peak. Specific peak identity was determined with hydrocarbon standards and by matching diagnostic peaks with those from prior studies (Jurenka et al., 1989; Liang et al., 2001).

Statistical Analyses. The significance of main effects (diet and initial aggression category) and their interaction was tested by using a mixed model ANOVA (PROC MIXED) in SAS 8.1 (SAS Institute, 2002). Upon finding that the effect of diet was not the same in the two aggression categories, we tested for the effect of diet on aggression loss within each of the two aggression categories with colony pairing and diet treated as random and fixed variables, respectively (ANOVA, PROC MIXED). Differences between the three dietary treatments within and across aggression categories were determined with leastsquares means. To analyze the magnitude of aggression loss, we used absolute, rather than relative, aggression loss values.

We used linear discriminant analysis (LDA) (Statgraphics Plus, v. 5.1) to examine hydrocarbon divergence patterns between field-collected colonies (Initial) and the same colonies raised on each of the three diets (Blattella, Supella, and Artificial). The analysis was performed using standardized variables, and an LDA matrix was constructed with 11 colonies, belonging to each of four treatments (Initial, Blattella, Supella, and Artificial), using 27 peak percentages of the most abundant cuticular hydrocarbons. Significance tests comparing diets used the MANOVA procedure (PROC GLM). The degree of dispersion around the centroids (i.e., the degree of differentiation between colonies within a treatment) was calculated by averaging standard deviations for each of the 11 colonies across all 27 hydrocarbons within each treatment. To test whether Argentine ants acquired key prey-specific hydrocarbons, we first identified key diagnostic hydrocarbons provided by each prey. For B. germanica, we selected peaks corresponding to 11-, 13-, and 15-methylnonacosane and 3-methylnonacosane. Both hydrocarbons are relatively abundant in adult $B$. germanica, comprising approximately 14.5 and $10.3 \%$ of the total hydrocarbons, respectively (Jurenka et al., 1989). Furthermore, our preliminary analysis indicated that both hydrocarbons were readily acquired by Argentine ants. For S. longipalpa, we selected 15,19-dimethylheptatriacontane present in S. longipalpa at $19.0 \%$ and acquired by Argentine ants from $S$. longipalpa prey (Liang and Silverman, 2000; Liang et al., 2001). To compare changes in individual hydrocarbon levels (average level on day 140 vs. average level on day 0), we used one of two types of $t$-tests, depending on the equality of variances. A parametric $t$-test was used when the variances were homogenous. In cases where the variances were unequal, we used the Welch $t$-test with a Satterthwaite correction (Zar, 1999). 


\section{RESULTS}

Analysis of the behavioral data revealed that the interaction between diet and aggression was significant (ANOVA, $F_{2,15.1}=13.38, P<0.001$ ). Because the diet effects were not the same in the two aggression categories, a separate analysis of diet effects for each aggression category was performed. Colony pairs experienced a significant reduction in initial aggression, irrespective of the diet (Table 1 and Figure 1). The aggression scores in colonies that were initially moderately aggressive and reared on either of the two cockroach diets decreased by $\sim 40 \%(P=0.91$, Table 2$)$. Ants raised on the artificial diet, however, experienced an $\sim 70 \%$ loss in initial aggression scores, which was significantly higher than that experienced by ants raised on either $B$. germanica $(P<0.001)$ or $S$. longipalpa $(P<0.001)$. Argentine ants displaying high initial aggression experienced relatively little change in aggression, approximately $8 \%$ loss for each of the three dietary regimes. This decrease, although relatively low, was statistically significant for each of the three diets (Table 1), and the magnitude of aggression loss did not differ between dietary categories (Table 2; ANOVA, $\left.F_{2,18}=0.72, P=0.50\right)$. A comparison of the magnitude of aggression loss between the aggression categories revealed that moderately aggressive colony pairs lost a significantly higher proportion of their initial aggression across all dietary treatments, relative to colony pairs showing high initial aggression (Table 2). Results of aggression tests performed $84 \mathrm{~d}$ after the first testing revealed no further aggression loss in any of the aggression/diet categories $(P>0.05)$.

To provide another measure of the magnitude of aggression loss in both aggression categories, we recorded changes in the proportion of injurious/

Table 1. Initial Aggression Levels and Aggression Loss in Moderately and Highly Aggressive Colony Pairings Reared Under Three Dietary Regimes

\begin{tabular}{|c|c|c|c|c|c|c|}
\hline \multirow{3}{*}{$\begin{array}{l}\text { Aggression } \\
\text { category }\end{array}$} & \multirow{3}{*}{$\begin{array}{c}\text { Initial } \\
\text { aggression } \\
\text { level }^{a}\end{array}$} & \multicolumn{5}{|c|}{ Aggression loss } \\
\hline & & \multicolumn{5}{|c|}{ Change } \\
\hline & & Diet & End & Absolute & Relative & $P^{b}$ \\
\hline \multirow[t]{3}{*}{ Moderate } & $2.79 \pm 0.08$ & Supella & $1.7 \pm 0.2$ & $1.1 \pm 0.2$ & $39.5 \pm 7.1 \%$ & $<0.001$ \\
\hline & $(n=8)$ & Blattella & $1.8 \pm 0.2$ & $1.0 \pm 0.2$ & $36.7 \pm 5.7 \%$ & $<0.001$ \\
\hline & & Artificial & $0.8 \pm 0.2$ & $2.0 \pm 0.2$ & $73.0 \pm 7.0 \%$ & $<0.001$ \\
\hline \multirow[t]{3}{*}{ High } & $4.00 \pm 0.00$ & Supella & $3.7 \pm 0.1$ & $0.3 \pm 0.1$ & $8.3 \pm 2.2 \%$ & 0.002 \\
\hline & $(n=10)$ & Blattella & $3.8 \pm 0.1$ & $0.2 \pm 0.1$ & $5.5 \pm 2.1 \%$ & 0.009 \\
\hline & & Artificial & $3.8 \pm 0.1$ & $0.2 \pm 0.1$ & $5.8 \pm 2.4 \%$ & 0.018 \\
\hline
\end{tabular}

${ }^{a}$ Initial aggression levels are between pairs of field-collected colonies. Values reported are mean \pm SE.

${ }^{b}$ ANOVA on absolute change (SAS Institute, 2002). 


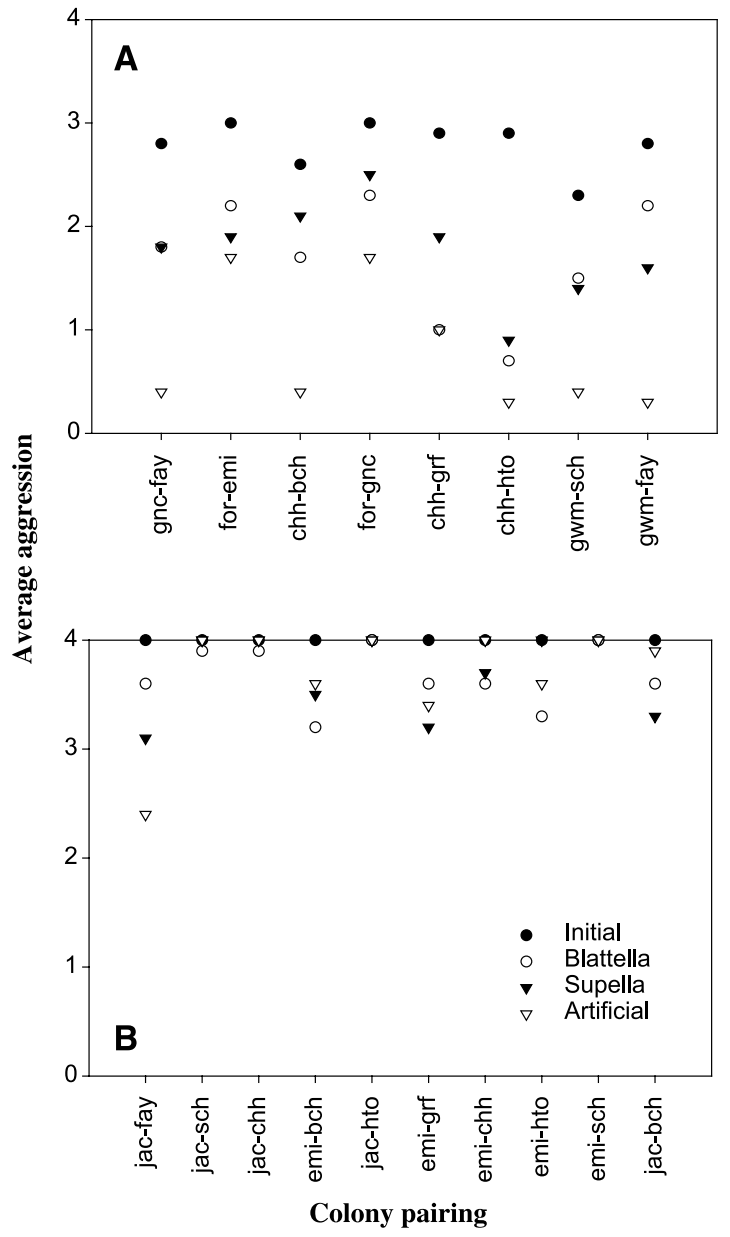

FIG. 1. Changes in intraspecific aggression in moderately (A) and highly (B) aggressive colony pairings. Field-collected colonies (Initial, closed circles) raised on one of three diets: Blattella (open circles), Supella (closed triangles), and artificial (open triangles). Mean values are reported $(n=10)$ with error bars omitted for clarity. See Methods and Materials for explanation of colony codes.

noninjurious encounters between colony pairs. Our initial aggression classification (moderate vs. high) was based on a distinction between injurious and noninjurious aggression. We classified aggression above level 3 as injurious (biting, stinging) and aggression below level 3 as noninjurious (mutual antennation, avoidance). Although the magnitude of aggression loss was statistically 
Table 2. Comparison of Aggression loss Within and Among Aggression CATEGORIES

\begin{tabular}{lllllcc}
\hline \multicolumn{1}{c}{ Diet } & Aggression & $\begin{array}{c}\text { Aggression } \\
\text { loss }\end{array}$ & Diet & Aggression & $\begin{array}{c}\text { Aggression } \\
\text { loss }\end{array}$ & $P^{a}$ \\
\hline Supella & Moderate & $1.1 \pm 0.2$ & Blattella & Moderate & $1.0 \pm 0.2$ & 0.91 \\
Supella & Moderate & $1.1 \pm 0.2$ & Artificial & Moderate & $2.0 \pm 0.2$ & $<0.001$ \\
Blattella & Moderate & $1.0 \pm 0.2$ & Artificial & Moderate & $2.0 \pm 0.2$ & $<0.001$ \\
Supella & High & $0.3 \pm 0.1$ & Blattella & High & $0.2 \pm 0.1$ & 0.42 \\
Supella & High & $0.3 \pm 0.1$ & Artificial & High & $0.2 \pm 0.1$ & 0.25 \\
Blattella & High & $0.2 \pm 0.1$ & Artificial & High & $0.2 \pm 0.1$ & 0.73 \\
Supella & High & $0.3 \pm 0.1$ & Supella & Moderate & $1.1 \pm 0.2$ & 0.001 \\
Blattella & High & $0.2 \pm 0.1$ & Blattella & Moderate & $1.0 \pm 0.2$ & $<0.001$ \\
Artificial & High & $0.2 \pm 0.1$ & Artificial & Moderate & $2.0 \pm 0.2$ & $<0.001$ \\
\hline
\end{tabular}

${ }^{a}$ Least squares analysis (SAS Institute, 2002).

significant in each of the two aggression categories, our results indicated that in contrast to pairs displaying moderate aggression, the incidence of injurious fights between highly aggressive pairs remained high. Therefore we question the biological importance of the statistically significant aggression loss between highly aggressive colony pairs. Among moderately aggressive pairs, initially 69 of $80(86 \%)$ encounters resulted in an aggression score of 3 or 4 (three out of 80 had an aggression score of 4 ). At the end of the study, only $36 \%$ of Supella-fed ants (corresponding to a 58\% reduction in the number of injurious encounters), $36 \%$ of Blattella-fed ants (58\% reduction), and $19 \%$ of ants on the artificial diet (78\% reduction) displayed level 3 aggression. In contrast, among highly aggressive colonies, initially all encounters (100/100) scored level 4. At the end of the study, $96 \%$ of Supella-fed ants (4\% reduction), 97\% of Blattella-fed ants (3\% reduction), and $98 \%$ of ants on the artificial diet ( $2 \%$ reduction) still engaged in injurious aggression. Level 4 aggression remained in $71 \%$ of Supella-fed ants, $78 \%$ of Blattella-fed ants, and $79 \%$ of ants fed with artificial diet.

Argentine ants acquired significant levels of prey hydrocarbons (Figure 2) Blattella: 11-, 13-, and 15-methylnonacosane $(P<0.001)$, 3-methylnonacosane $(P<0.001)$ and Supella: 15,19-dimethylheptatriacontane $(P<0.001)$. Because $S$. longipalpa hydrocarbons overlap the long-chain hydrocarbon profile of L. humile (Liang et al., 2001), field-collected colonies of Argentine ants possess relatively high initial levels of hydrocarbons specific to S. longipalpa (Figure 2C). However, there are certain qualitative and quantitative differences between L. humile hydrocarbons and those provided by S. longipalpa. Consequently, providing Argentine ants with $S$. longipalpa prey would likely alter the relative ratio of hydrocarbons already present as well as introduce new hydrocarbons. Furthermore, the results of discriminant analysis revealed marked 


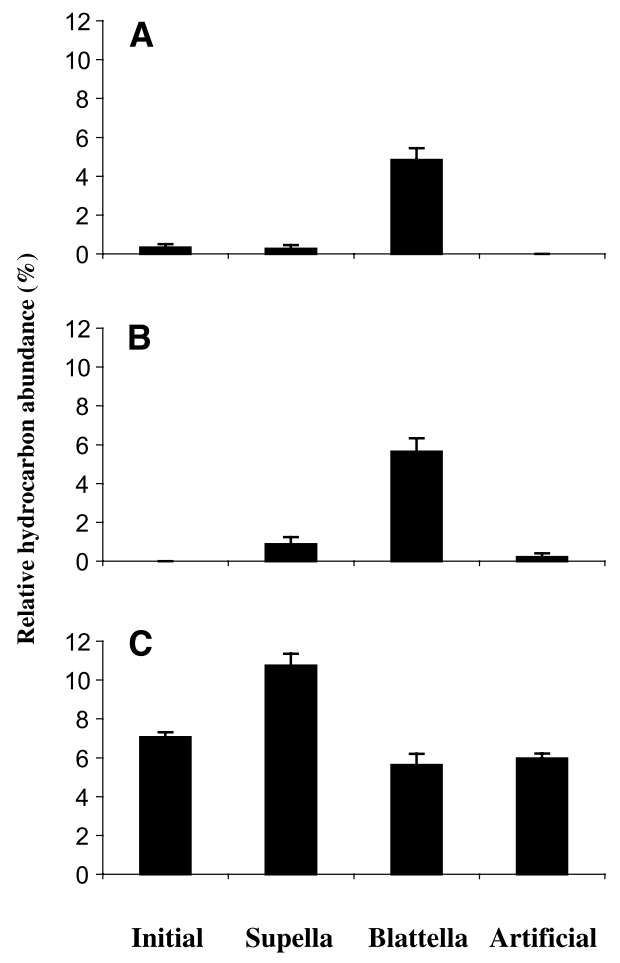

FIG. 2. Relative abundance (\% total area) of key prey-derived hydrocarbons in fieldcollected colonies of $L$. humile (Initial) and colonies provisioned with one of prey diets: S. longipalpa (Supella) and B. germanica (Blattella). Hydrocarbons (A) and (B) are Blattella-derived and (C) is Supella-derived. (A) 11-, 13-, and 15-methylnonacosane; (B) 3-methylnonacosane; (C) 15,19-dimethylheptatriacontane. Means \pm SE for 11 colonies are presented.

divergence in cuticular hydrocarbon composition between field-collected colonies (Initial) and colonies raised on either B. germanica, S. longipalpa, or the artificial diet (Figure 3): Initial vs. Blattella (MANOVA, Wilk's lambda = $0.0028, F_{26,5}=67.04, P<0.001$ ), Initial vs. Supella (Wilk's lambda $=0.010$, $F_{26,5}=18.16, P=0.002$ ), and Initial vs. Artificial (Wilk's lambda $=0.010$, $\left.F_{26,5}=18.94, P=0.002\right)$. The divergence between the Blattella and Supella diets was also significant (Wilk's lambda $=0.0066, F_{26,5}=28.88, P<0.001$ ). Estimates of intracolony variability within treatments revealed that field-collected colonies (Initial) had the lowest variance (1.029), followed by colonies on the artificial diet (1.035), Supella (1.147), and Blattella (1.209). Changes in the proportions of the 27 most abundant cuticular hydrocarbons are summarized 


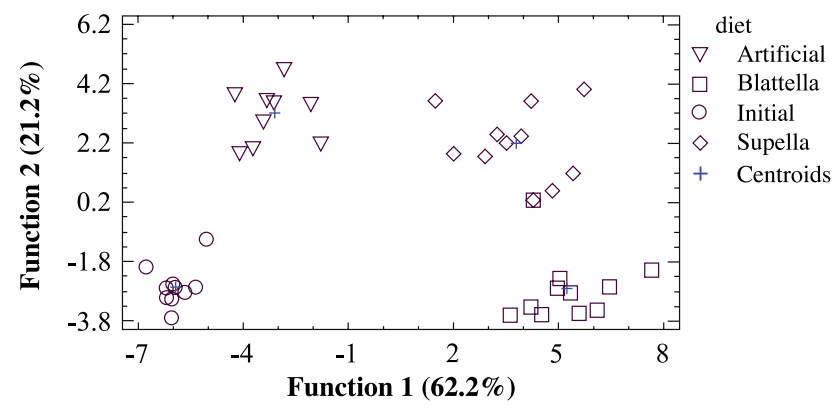

FIG. 3. Linear discriminant analysis of the 27 predictor variables (relative proportions of hydrocarbons) for 11 colonies of $L$. humile each provided a unique diet (B. germanica, S. longipalpa, and artificial).

in Table 3. Overall, colonies raised on all three diets experienced changes in the proportions of all hydrocarbons. In colonies raised on the artificial diet, six hydrocarbons significantly increased and eight hydrocarbons significantly decreased (52\% of hydrocarbons changed significantly). In colonies raised on Blattella, five hydrocarbons significantly increased and 12 hydrocarbons significantly decreased (63\% change). Colonies raised on Supella experienced the greatest change $(67 \%)$, with seven hydrocarbons increasing and 11 hydrocarbons decreasing over the course of the study.

\section{DISCUSSION}

Our results provide further support for Argentine ant nestmate recognition being modulated, in part, by environmental factors (Chen and Nonacs, 2000; Liang and Silverman, 2000), in that rearing under controlled conditions reduces aggression between colonies. Prior studies (Liang and Silverman, 2000; Liang et al., 2001) demonstrated that exogenous hydrocarbons disrupted L. humile colony integrity by inducing aggression between fragments of the same colony. Herein, we determined that shared diet reduced intercolony aggression to an extent that might promote fusion of dissimilar colonies.

Changes in aggression were minimal between colony pairs that were initially highly aggressive, despite worker ants acquiring prey hydrocarbons. Therefore limited change in the pattern of intraspecific aggression within the highly aggressive pairings suggests that exogenous recognition cues did not override intrinsic cues, which may help to explain the results of other ant studies in which aggression persisted over time (Le Moli et al., 1992; Heinze et al., 1996; Holway et al., 1998; Stuart and Herbers, 2000; Suarez et al., 2002). In 
Table 3. Twenty-SEven Most Abundant Cuticular Hydrocarbons AND their CHANGES Following REARING ON LABORATORY DIETS

\begin{tabular}{|c|c|c|c|}
\hline \multirow[b]{2}{*}{ Hydrocarbon } & \multicolumn{3}{|c|}{ Diet } \\
\hline & Artificial & $\begin{array}{l}\text { Blattella } \\
\text { germanica }\end{array}$ & $\begin{array}{c}\text { Supella } \\
\text { longipalpa }\end{array}$ \\
\hline$n$-Heptadecane & 0 & 0 & + \\
\hline Nonadecene & 0 & + & $+*$ \\
\hline$n$-Tricosane & - & - & - \\
\hline$n$-Pentacosane & - & - & - \\
\hline$n$-Heptacosane & $+*$ & $+*$ & $+*$ \\
\hline$n$-Octacosane & $+*$ & + & $+*$ \\
\hline$n$-Nonacosane & $+*$ & $+*$ & $+*$ \\
\hline 11-, 13-, and 15-Methylnonacosane & - & $+*$ & - \\
\hline 3-Methylnonacosane & + & $+*$ & $+*$ \\
\hline$n$-Triacontane & + & $+*$ & + \\
\hline$n$-Hentriacontane & $+^{*}$ & - & + \\
\hline 11-, 13-, and 15-Methylhentriacontane & - & - & $-*$ \\
\hline Dimethylhentriacontane & $+*$ & - & + \\
\hline Trimethylhentriacontane & $-*$ & - & + \\
\hline$n$-Tritriacontane & - & $-*$ & $-*$ \\
\hline 13- and 15-Methyltritriacontane & $-*$ & $-*$ & $-*$ \\
\hline 5,15- and 5,17-Dimethyltritriacontane & - & $-*$ & $-*$ \\
\hline $5,15,19$-Trimethyltritriacontane & - & $-*$ & $+^{*}$ \\
\hline 13-, 15-, and 17-Methylpentatriacontane & $-*$ & $-*$ & $-*$ \\
\hline 15,19-Dimethylpentatriacontane & $+^{*}$ & $-*$ & $-*$ \\
\hline 5,15- and 5,17-Dimethylpentatriacontane & $-*$ & $-*$ & $-*$ \\
\hline $5,13,17$ - and $5,15,19$-Trimethylpentatriacontane & - & $-*$ & $-*$ \\
\hline $3,13,17$ - and $3,15,17$-Trimethylpentatriacontane & $-*$ & $-*$ & - \\
\hline 13-, 15-, 17-, and 19-Methylheptatriacontane & $-*$ & $-*$ & $-*$ \\
\hline 15,19-Dimethylheptatriacontane & $-*$ & - & $+^{*}$ \\
\hline 5,15- and 5,17-Dimethylheptatriacontane & $-*$ & $-*$ & $-*$ \\
\hline $5,15,19-$ and $5,13,17$-Trimethylheptatriacontane & - & $-*$ & $-*$ \\
\hline Significant changes & $+(6),-(8)$ & $+(5),-(12)$ & $+(7),-(11)$ \\
\hline
\end{tabular}

*Significant change in hydrocarbon proportion $(P<0.05$; Student's $t$-test $)$.

contrast, colonies in pairings that were initially moderately aggressive were strongly affected by the imposition of diet-based cues. We predicted that exposure to cockroach prey, especially $S$. longipalpa, would provide abundant hydrocarbons that could minimize between-colony recognition disparities, thereby producing the greatest decline in aggression. However, intraspecific aggression in ants fed with artificial diet diminished further than aggression in ants fed with cockroaches, indicating that the greatest change in behavior may be a consequence of the field-to-lab transition. Hydrocarbon profiles of $L$. humile raised on the artificial diet changed significantly over time; however, the hydrocarbons 
(and/or chemical cues) affecting this behavioral change are unclear. Moreover, the difference in the degree of aggression loss between the two prey diets was not significant, an unexpected result given that long-chain hydrocarbons from $S$. longipalpa (33 carbons or more) added to the native L. humile cuticular profile induced intracolony aggression, whereas other prey items from diverse insect taxa (including B. germanica), having fewer or none of these long-chain hydrocarbons, induced little or no within-colony aggression (Liang et al., 2001). The action of prey hydrocarbons in promoting intercolony unity appears to differ from that inducing intracolony aggression. Perhaps the difference in the way prey hydrocarbons alter nestmate recognition in L. humile is related to quantitative differences in hydrocarbon levels needed to affect a behavioral change. Thus, where two antagonistic fragments were created from a single colony (Silverman and Liang, 2001), the acquisition of one or a few key hydrocarbons produced a recognizable shift in an otherwise uniform profile. In the current study, the acquisition of foreign prey hydrocarbons appeared insufficient to completely override intrinsic distinctions between colonies.

Our findings may provide insights into the evolution of unicoloniality in introduced populations of the Argentine ant. Proposed mechanisms for the transition from multi- to unicoloniality include reduced heterozygosity due to genetic drift (Tsutsui et al., 2000) and introduction to new habitats with relaxed ecological constraints (Giraud et al., 2002), with unicoloniality maintained via selection against rare recognition alleles (Tsutsui et al., 2003). Whereas Tsutsui et al. $(2000,2003)$ and Giraud et al. (2002) demonstrated the importance of genetic, ecological, and behavioral factors in the transition from multicoloniality to unicoloniality, we suggest that shared environmentally derived recognition cues may promote unicoloniality by masking inherent betweencolony distinctions, thereby allowing adjacent colonies to fuse. Competing Argentine ant colonies will most likely interact with each other at advancing invasion fronts where they are likely to compete for nesting sites and/or food resources that provide similar nestmate recognition cues. In areas where mutually aggressive colonies exploit a common locally abundant food source, two mechanisms may work independently or together to promote fusion of neighboring colonies: diet sharing and intraspecific "dear enemy" phenomenon, whereby competing animals respond less aggressively to threats by neighbors than strangers (Temeles, 1994; Heinze et al., 1996; Langen et al., 2000). Diet sharing through cooperative use of locally abundant food sources may provide sufficient levels of critical hydrocarbons to alter nestmate recognition and promote fusion of colonies. Argentine ants, like other invasive ants, are generalist feeders (Newell and Barber, 1913; Markin, 1970), tending homoptera and scavenging living and dead arthropods. In addition, shared cues originating from nesting material may diminish intercolony aggression. The "dear enemy" phenomenon may also play a role in the Argentine ant's transition from multicoloniality to 
unicoloniality. An increase in the frequency of encounters between aggressive colonies may decrease the frequency of aggression between them, especially in areas where food is abundant and intraspecific competition is limited (Foitzik and Heinze, 1998). Furthermore, repeated interactions in the field were essential for maintaining recognition among spatially isolated nests in the polydomous Leptothorax longispinosus with nonaggressive field colonies becoming hostile after 3 mo of laboratory rearing, thereby indicating a possible role for common environment-derived cues and/or contact between colonies in reducing aggression (Stuart and Herbers, 2000). Where Argentine ants interact and compete for resources that provide common recognition cues, cooperation among nests through a reduction in intercolony aggression may be promoted. However, an exception may occur within the native range, where L. humile is multicolonial despite neighboring colonies presumably having access to shared environmentderived cues. Native L. humile exhibit relatively high genetic diversity and high intercolony aggression (Tsutsui et al., 2000); consequently, environmentally derived recognition cues may be limited in diminishing intercolony aggression. However, colonies from invasive populations having weaker genetic structure (Tsutsui and Case, 2001; Buczkowski et al., 2004) may be more likely to fuse when exogenous cues mask colony distinctions, thereby fostering the development of unicoloniality.

Acknowledgments-We thank C. Apperson, C. Schal, E. Vargo, and two anonymous reviewers for helpful comments on the manuscript, G. Blomquist for providing hydrocarbon standards and for technical input, A. Carper for technical assistance, C. Brownie and J. Smith for statistical advice, and D. Dillingham, G. Kirby, and D. Suiter for help in locating ant colonies. This study was supported by the Blanton J. Whitmire Endowment at North Carolina State University.

\section{REFERENCES}

BhatKaR, A. D. and Whitcomb, W. H. 1970. Artificial diet for rearing various species of ants. Fla. Entomol. 53:229-232.

Buczkowski, G., Vargo, E. L., and Silverman, J. 2004. The diminutive supercolony: The Argentine ants of the southeastern United States. Mol. Ecol. 13:2235-2242.

CHEN, J. S. C. and NonACS, P. 2000. Nestmate recognition and intraspecific aggression based on environmental cues in Argentine ants (Hymenoptera: Formicidae). Ann. Entomol. Soc. Am. 93:1333-1337.

FoitzIK, S. and HeinZe, J. 1998. Nestsite limitation and colony take over in the ant, Leptothorax nylanderi. Behav. Ecol. 9:367-375.

GamboA, G. J., ReEve, H. K., Ferguson, I. D., and Wacker, T. L. 1986. Nestmate recognition in social wasps: The origin and acquisition of recognition odours. Anim. Behav. 34:685-695.

Giraud, T., Pedersen, J. S., and Keller, L. 2002. Evolution of supercolonies: The Argentine ants of southern Europe. Proc. Natl. Acad. Sci. USA 99:6075-6079.

HeINZE, J., FoITZIK, S., HipPERT, A., and HÖLldobler, B. 1996. Apparent dear-enemy phenomenon 
and environment-based recognition cues in the ant Leptothorax nylanderi. Ethology 102:510-522.

Holway, D. A., SuAREZ, A. V., and CASE, T. J. 1998. Loss of intraspecific aggression in the success of a widespread invasive social insect. Science 282:949-952.

ICHINOSE, K. 1991. Seasonal variation in nestmate recognition in Paratrechina flavipes (Smith) worker ants (Hymenoptera: Formicidae). Anim. Behav. 41:1-6.

Jutsum, A. R., SAunders, T. S., and Cherrett, J. M. 1979. Intraspecific aggression in the leafcutting ant Acromyrmex octospinosus. Anim. Behav. 27:839-844.

Jurenka, R. A., Schal, C., Burns, E., Chase, J., and Blomquist, G. J. 1989. Structural correlation between cuticular hydrocarbons and female contact sex pheromone of German cockroach Blattella germanica (L.). J. Chem. Ecol. 15:939-949.

Lahav, S., Soroker, V., Hefetz, A., and Vander Meer, R. K. 1999. Direct behavioral evidence for hydrocarbons as ant recognition discriminators. Naturwissenschaften 86:246-249.

Langen, T. A., Tripet, F., and Nonacs, P. 2000. The red and the black: Habituation and the dearenemy phenomenon in two desert Pheidole ants. Behav. Ecol. Sociobiol. 48:285-292.

Le Moli, F., Mori, A., and Grasso, D. A. 1992. Nestmate and conspecific non-nestmate recognition in Formica cunnicularia Latr.: The effect of diet difference, pp. 161-165, in J. Billen (ed.). Biology and Evolution of Social Insects. Leuven University Press, Leuven, Belgium.

LiAnG, D. and Silverman, J. 2000. "You are what you eat": Diet modifies cuticular hydrocarbons and nestmate recognition in the Argentine ant, Linepithema humile. Naturwissenschaften $87: 412-416$.

Liang, D., BlomQuist, G. J., and Silverman, J. 2001. Hydrocarbon-released nestmate aggression in the Argentine ant, Linepithema humile, following encounters with insect prey. Comp. Biochem. Physiol. 129:871-882.

Markin, G. P. 1970. The seasonal life cycle of the Argentine ant, Iridomyrmex humilis (Hymenoptera: Formicidae) in southern California. Ann. Entomol. Soc. Am. 63:1238-1242.

Newell, W. and BARBER, T. C. 1913. The Argentine Ant. USDA Bureau of Entomology Bulletin 122.

OBIN, M. S. and VANDER MeER, R. K. 1988. Sources of nestmate recognition cues in the imported fire ant Solenopsis invicta Buren (Hymenoptera: Formicidae). Anim. Behav. 36:1361-1370.

Roulston, T. H., Buczkowski, G., and Silverman, J. 2003. Nestmate discrimination in ants: Effect of bioassay on aggressive behavior. Insectes Soc. 50:151-159.

SAS InSTITUTE 2002. SAS/STAT Guide for Personal Computers, version 8.1. SAS Institute, Cary, NC.

Silverman, J. and LiANG, D. 2001. Colony disassociation following diet partitioning in a unicolonial ant. Naturwissenschaften 88:73-77.

STUART, R. J. 1987. Transient nest mate recognition cues contribute to a multicolonial population structure in the ant, Leptothorax curvispinosus. Behav. Ecol. Sociobiol. 21:229-235.

Stuart, R. J. and Herbers, J. M. 2000. Nest mate recognition in ants with complex colonies: Within- and between-population variation. Behav. Ecol. 11:676-685.

Suarez, A. V., Tsutsui, N. D., Holway, D. A., and Case, T. J. 1999. Behavioral and genetic differentiation between native and introduced populations of the Argentine ant. Biol. Inv. $1: 43-53$.

Suarez, A. V., Holway, D. A., Liang, D., Tsutsui, N. D., and Case, T. J. 2002. Spatio-temporal patterns of intraspecific aggression in the invasive Argentine ant. Anim. Behav. 64:697-708.

TEMELES, E. J. 1994. The role of neighbors in territorial systems: When are they "dear enemies?" Anim. Behav. 47:339-350.

Tsutsui, N. D. and CASE, T. J. 2001. Population genetics and colony structure of the Argentine ant (Linepithema humile) in its native and introduced ranges. Evolution 55:976-985. 
Tsutsui, N. D., Suarez, A. V., Holway, D. A., and Case, T. J. 2000. Reduced genetic variation and the success of an invasive species. Proc. Natl. Acad. Sci. USA 97:5948-5953.

Tsutsui, N. D., SuArez, A. V., and GrosberG, R. K. 2003. Genetic diversity, asymmetrical aggression, and recognition in a widespread invasive species. Proc. Natl. Acad. Sci. USA 100: $1078-1083$.

Vander Meer, R. K., SaliwanchiK, D., and Lavine, B. 1989. Temporal changes in colony cuticular hydrocarbon patterns of Solenopsis invicta: Implications for nestmate recognition. $J$. Chem. Ecol. 15:2115-2125.

VANDer Meer, R. K. and Morel, L. 1998. Nestmate recognition in ants, pp. 79-103, in R. K. Vander Meer, M. D. Breed, K. E. Espiele, and M. L. Winston (eds.). Pheromone Communication in Social Insects. Westview Press, Boulder, CO.

ZAR, J. H. 1999. Biostatistical Analysis. Prentice Hall, New Jersey. 